\title{
Regimen Used to Treat Breast Carcinoma
}

National Cancer Institute

\section{Source}

National Cancer Institute. Regimen Used to Treat Breast Carcinoma. NCI Thesaurus.

Code C63358.

Any regimen that can be used for the treatment of breast cancer. 